\title{
STRATEGI KOPING PADA REMAJA LAKI-LAKI DI RUMAH TAHANAN KELAS I BANDUNG, JAWA BARAT
}

\author{
Fatma Sayekti Ruffaida \\ Universitas Kadiri
}

\begin{abstract}
ABSTRAK
Remaja mempunyai risiko tinggi terhadap gangguan tingkah laku, kenakalan dan terjadinya kekerasan baik sebagai korban maupun sebagai pelaku dari tindak kekerasan. Strategi koping sangat penting dalam keperawatab karena semua klien mengalami tekanan sehingga memerlukan kemampuan strategi koping untuk mengatasi tekanan. Tujuan dari penelitian ini adalah untuk mengidentifikasi strategi koping remaja laki-laki di Rumah Tahanan Kelas I Bandung, Jawa Barat. Penelitian ini dirancang dalam jenis penelitian cross-sectional. Instrumen yang digunakan berupa kuesioner yang dibagikan kepada 89 remaja laki-laki. Data dianalisis menggunakan analisa deskriptif. Hasil penelitian menunjukan bahwa remaja laki-laki di Rumah Tahanan Kelas I Bandung hampir setengah responden (39,33\%) menggunakan strategi koping yang berpusat pada masalah dan emosi, sebagian kecil responden $(10,11 \%)$ menggunakan strategi koping yang berpusat pada masalah, dan sebagian kecil responden (17,98\%) menggunakan strategi koping yang berpusat pada emosi. Dari hasil penelitian ini diharapkan pemberi layanan kesehatan meningkatkan perhatian mengenai kondisi internal dan eksternal pada remaja laki-laki di Rumah Tahanan Kelas 1 Bandung. Perawat juga diharapkan dapat melaksanakan asuhan keperawatan yang optimal, sehingga remaja laki-laki di Rumah Tahanan Kelas I Bandung dapat memberikan respon yang adaptif dalam menjalani masa penahanan. Pengkajian lebih lanjut mengenai faktor-faktor yang mempengaruhi penggunaan strategi koping perlu dilaksanakan untuk membuat strategi koping yang efektif untuk remaja laki-laki.
\end{abstract}

Kata kunci: strategi koping, remaja laki-laki dan rumah tahanan

\begin{abstract}
Adolescents have high risks of behavior disorder, juvenile, and abuse, not only as a victim, but also as offender. Coping strategy is important in nursing because all of the clients have stressors. Thus, the clients need the ability of coping strategy to cope with stressors. The aim of this investigation was to identify coping strategy of male adolescence in jail. A cross-sectional study was conducted in this study. The questionnaire was distributed to 89 male adolescences. The results revealed that almost half of male adolescents $(39,33 \%)$ used both of coping strategy Few of male adolescents $(10,11 \%)$ used problem focused coping and few of male adolescents (17,98\%) used emotion focused coping. Based on these findings, health care providers should concern about the internal and external conditions among male adolescents in First Class Jail Bandung. In addition, nurses should perform the nursing care optimally in order to establish the adaptive response of male adolescents during their incarceration. Further assessments are needed to determine the factors predicting coping strategy to design the appropriate coping strategy for adolescents. Keywords: coping strategy, male adolescents, and jail
\end{abstract}

Jurnal IImu Keperawatan, Vol:4, No.1 Mei 2016 ,; Korespondensi : Fatma S. Ruffaida. Universitas Kadiri. Jl. Selomangleng No. 1 Kediri. E-mail: fatma.ruffaida@gmail.com

Jurnal Ilmu Keperawatan - Volume 4, No. 1 Mei 2016 


\section{PENDAHULUAN}

Masa remaja merupakan masa peralihan antara masa kanak-kanak dan masa dewasa yang dimulai pada saat terjadinya kematangan seksual, yaitu antara usia 11 atau 12 tahun sampai dengan 20 tahun, yaitu menjelang usia dewasa muda. Remaja tidak mempunyai tempat yang jelas, yaitu bahwa mereka tidak termasuk golongan anak-anak tetapi tidak juga termasuk golongan orang dewasa (Marheni dalam Soetjiningsih, 2004). Perhatian pada kelompok remaja sangat penting karena remaja merupakan populasi yang besar, baik Indonesia, Jawa Barat bahkan kota Bandung. Hasil statistik dari Biro Pusat Statistik menyebutkan bahwa populasi penduduk Indonesia pada tahun 2000 berusia 10-24 tahun mencapai 61 juta jiwa atau 30,24 persen dari total penduduk yang jumlahnya 206,3 juta jiwa. Di Propinsi Jawa Barat sendiri, hasil statistik menunjukkan bahwa populasi penduduk pada tahun 2000 berusia 10-24 tahun mencapai 11 juta jiwa atau 30,8 persen dari total penduduk Jawa Barat yang jumlahnya 35,72 juta jiwa. Pada tahun 2010, diperkirakan populasi penduduk yang berusia 10-24 tahun mencapai 12 juta jiwa atau 27,27 persen dari total penduduk Jawa Barat yang diproyeksikan berjumlah 44 juta jiwa (Biro Pusat Statistik, 2000). Remaja juga mempunyai risiko tinggi terhadap gangguan tingkah laku, kenakalan dan terjadinya kekerasan baik sebagai korban maupun sebagai pelaku dari tindak kekerasan. Pada masa remaja sering didapatkan adanya gangguan tingkah laku (conduct disorder) yang melanggar norma-norma sosial yang berlaku. Semakin banyak pula remaja yang ditahan karena melakukan tindak kriminalitas yang digolongkan sebagai kenakalan remaja (juvenile deliquent) (Windiani dan Soetjiningsih dalam Soetjiningsih, 2004). Menurut Kartono (1997) dalam Simatupang dan Irmawati (2006), meskipun kejahatan dapat dilakukan oleh siapapun juga, umumnya yang lebih dominan dalam dunia kejahatan adalah kaum laki-laki. Rutter dkk (1998) dalam Simatupang dan Irmawati (2006) mendukung hal ini dengan menyatakan, telah menjadi suatu fakta yang diterima secara universal bahwa kejahatan lebih banyak dilakukan oleh laki-laki. Jumlah remaja yang berada dalam penjara di seluruh Indonesia sekitar tiga ribu orang. Setiap tahunnya terdapat lebih dari 4.000 perkara pelanggaran hukum yang dilakukan remaja di bawah usia 16 tahun. Dari seluruh remaja yang ditangkap sekitar separuhnya diajukan ke pengadilan dan 83 persen dari mereka kemudian dipenjarakan. Hingga tahun 2002, terdapat 3,722 remaja didik di LAPAS Remaja (Departemen Kehakiman dan HAM, 2008). Data di atas menunjukkan bahwa tindak kejahatan yang dilakukan remaja di Jawa Barat paling banyak dilakukan oleh remaja laki-laki dibandingkan dengan remaja wanita. Selain itu, 
data di atas juga menunjukkan bahwa jumlah tahanan dan narapidana yang berada di Rumah Tahanan Kelas I Bandung telah melebihi kapasitas rumah tahanan itu sendiri. Tanti (2007) menyatakan bahwa keadaan yang sangat padat pada rumah tahanan menjadi faktor yang dapat memicu timbulnya tingkat stres yang lebih tinggi. Oleh karena itu peneliti membatasi penelitian pada remaja laki-laki yang sedang ditahan. Penelitian terhadap strategi koping sangat penting dilakukan karena perawat berperan dalam membantu memfasilitasi kemampuan sistem adaptasi klien (individu, keluarga dan komunitas) dalam berespon terhadap masalah kesehatan atau potensial menjadi masalah kesehatan dengan menggunakan strategi koping yang paling efektif. Perawat adalah orang yang banyak menghabiskan waktu bersama klien dan keluarga atau teman mereka sehingga perawat adalah orang yang berada dalam posisi sangat penting untuk secara kritis menganalisis respon strategi koping (Potter dan Perry, 2005). Dalam keperawatan, konsep strategi koping sangat penting karena semua klien mengalami tekanan sehingga memerlukan kemampuan strategi koping untuk mengatasinya dan merupakan salah satu tugas dari seorang perawat untuk dapat mengembangkan strategi klien secara efektif sehingga klien dapat memenuhi kebutuhan dasarnya secara optimal (Potter dan Perry, 2005). Dengan intervensi lebih dini terhadap remaja di rumah tahanan diharapkan remaja tersebut tidak mengalami situasi yang penuh tekanan yang berkepanjangan dan mampu mengembangkan strategi koping yang lebih konstruktif. Tujuan dari penelitian ini adalah untuk mengidentifikasi strategi koping yang digunakan remaja laki-laki di rumah tahanan kelas I Bandung.

\section{METODE}

Desain penelitian cross-sectional digunakan dalam penelitian ini. Teknik sample yang digunakan adalah total-sampling dan diperoleh 89 responden. Variabel penelitian adalah strategi koping pada remaja laki-laki di rumah tahanan. Teknik pengumpulan data yang digunakan dalam penelitian ini adalah menggunakan kuisioner yang diisi sendiri oleh responden (self-administrated questionnaire). Instrumen yang digunakan untuk mengukur strategi koping dikembangkan dari kuisioner Ways of Coping oleh Lazarus dan Folkman (1984) dan dilakukan modifikasi sesuai dengan tujuan penelitian. Analisa data yang digunakan dalam penelitian ini adalah analisa univariat. Analisa univariat digunakan untuk menjelaskan atau menggambarkan karakteristik variabel yang diteliti, sehingga data hasil pengumpulan kuisioner dilihat melalui distribusi frekuensi.

\section{HASIL}

Hasil penelitian menunjukkan bahwa hampir setengah remaja laki-laki di rumah tahanan 
kelas I Bandung, yaitu 26 orang atau $29,21 \%$ berusia 17 tahun. Berdasarkan pendidikan, hampir setengah remaja laki-laki di rumah tahanan kelas I Bandung, yaitu 37 orang atau 41,57\% adalah berpendidikan SMP. Berdasarkan lama penahanan, hampir setengah remaja laki-laki di rumah tahanan kelas I Bandung, yaitu 29 orang atau 32,58\% adalah 24 bulan.

Tabel 1 Distribusi frekuensi berdasarkan usia, pendidikan, dan lama penahanan $(n=89$ responden).

\begin{tabular}{lcc}
\hline \multicolumn{1}{c}{ Variabel } & Frekuensi & Persentase \\
\hline Usia & & \\
13 tahun & 4 & $4,49 \%$ \\
14 tahun & 7 & $7,87 \%$ \\
15 tahun & 9 & $10,11 \%$ \\
16 tahun & 24 & $26,97 \%$ \\
17 tahun & 26 & $29,21 \%$ \\
18 tahun & 19 & $21,35 \%$ \\
Pendidikan & & \\
SD & 23 & $25,85 \%$ \\
SMP & 37 & $41,57 \%$ \\
SMA & 15 & $16,85 \%$ \\
SMK & 14 & $15,73 \%$ \\
Lama Penahanan & & \\
$0-2$ bulan & 11 & $12,37 \%$ \\
$2-4$ bulan & 29 & $32,58 \%$ \\
$4-6$ bulan & 16 & $17,98 \%$ \\
$6-8$ bulan & 9 & $10,11 \%$ \\
$8-10$ bulan & 9 & $10,11 \%$ \\
$10-12$ bulan & 6 & $6,74 \%$ \\
$>12$ bulan & 9 & $10,11 \%$ \\
\hline
\end{tabular}

Sumber : data primer yang diolah

Berdasarkan penggunaan strategi koping, dapat dilihat bahwa hampir setengah responden menggunakan strategi koping yang berpusat pada masalah dan emosi, yaitu 35 orang atau $39,33 \%$.

Tabel 2 Distribusi frekuensi berdasarkan penggunaan strategi koping ( $n=89$ responden).

\begin{tabular}{lcc}
\multicolumn{1}{c}{ Variabel } & Frekuensi & Persentase \\
\hline $\begin{array}{l}\text { Menggunakan strategi } \\
\text { koping yang berpusat } \\
\text { pada masalah }\end{array}$ & 9 & $10,11 \%$ \\
$\begin{array}{l}\text { Menggunakan strategi } \\
\text { koping yang berpusat } \\
\text { pada emosi }\end{array}$ & 16 & $17,98 \%$ \\
$\begin{array}{l}\text { Menggunakan strategi } \\
\text { koping yang berpusat } \\
\text { pada masalah dan } \\
\text { emosi }\end{array}$ & 35 & $39,33 \%$ \\
$\begin{array}{l}\text { Tidak menggunakan } \\
\text { strategi koping yang } \\
\text { berpusat pada masalah } \\
\text { atau emosi }\end{array}$ & 29 & $32,58 \%$
\end{tabular}

Sumber : data primer yang diolah

Berdasar pada indikator strategi koping yang berfokus pada masalah dapat dilihat bahwa sebagian besar responden, yaitu 48 orang atau $53,93 \%$ menggunakan indikator menentang masalah atau confrontative pada strategi koping yang berpusat pada masalah.

Tabel 3 Distribusi frekuensi strategi koping yang berpusat pada masalah ( $n=89$ responden).

\begin{tabular}{|c|c|c|c|c|}
\hline \multirow{2}{*}{ Variabel } & \multicolumn{3}{|c|}{ Menggunakan } & Tidak \\
\hline & $f$ & $\%$ & $f$ & $\%$ \\
\hline $\begin{array}{l}\text { Menentang masalah } \\
\text { (Confrontative } \\
\text { Coping) }\end{array}$ & 48 & 3,93 & 41 & 6,07 \\
\hline $\begin{array}{l}\text { Perencanaan } \\
\text { pemecahan masalah } \\
\text { (Planfull Problem } \\
\text { Solving) }\end{array}$ & 42 & 7,19 & 47 & 2,81 \\
\hline $\begin{array}{l}\text { Mencari dukungan } \\
\text { sosial (Seeking Social } \\
\text { Support) }\end{array}$ & 39 & 3,82 & 50 & 6,18 \\
\hline Sumber : data prim & eer $y$ & g dio & & \\
\hline
\end{tabular}


sebagian besar responden menggunakan indikator penilaian positif atau positive reappraisal, yaitu 51 orang atau 57,30\% pada strategi koping yang berpusat pada emosi.

Tabel 4 Distribusi frekuensi strategi koping yang berpusat pada emosi ( $n=89$ responden).

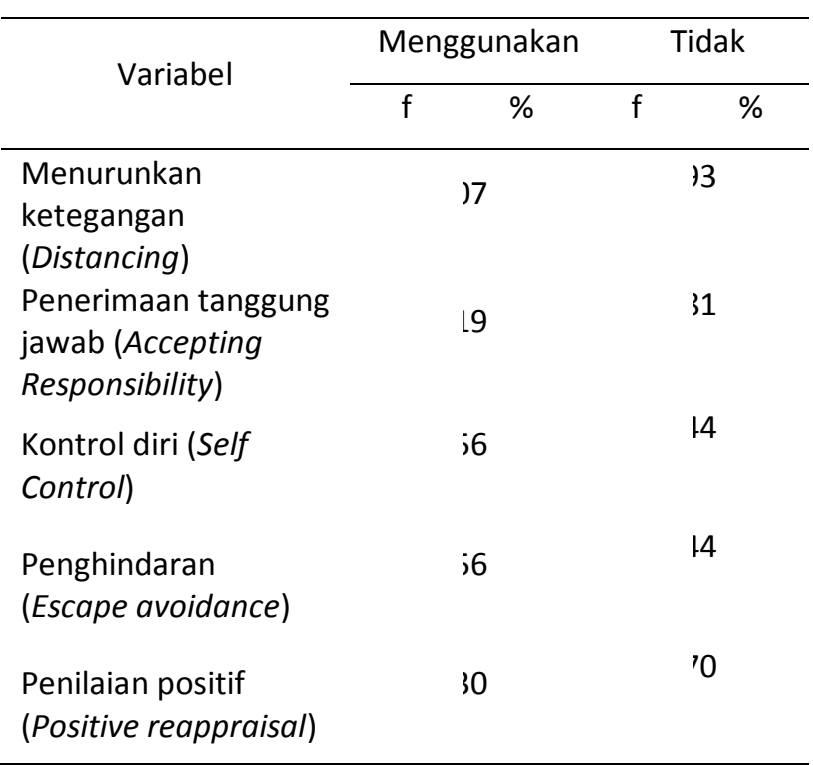

Sumber : data primer yang diolah

\section{PEMBAHASAN}

Berdasarkan hasil penelitian, dapat dilihat bahwa strategi yang berpusat pada masalah digunakan oleh 9 orang $(10,11 \%)$ atau sebagian kecil responden. Strategi koping yang berpusat pada masalah merupakan strategi koping yang dipusatkan untuk memecahkan masalah, diarahkan pada perumusan masalah yang menghasilkan berbagai alternatif pemecahan masalah dan bertindak (Lazarus dan Folkman, 1984). Hal ini menunjukkan bahwa remaja lakilaki di rumah tahanan akan berusaha mencari jalan keluar terhadap sesuatu yang menimbulkan masalah akibat penahanan. Seseorang akan cenderung menggunakan strategi koping ini bila dirinya yakin akan kemampuannya mengubah situasi yang penuh tekanan dan menimbulkan kecemasan. Banyaknya penggunaan strategi koping yang berpusat pada masalah dapat disebabkan oleh remaja laki-laki di Rumah Tahanan Kelas I Bandung hampir setengahnya $(29,21 \%)$ telah memasuki usia remaja akhir, yaitu 17 tahun sehingga remaja laki-laki di rumah tahanan tersebut telah mampu berpikir tentang kemungkinan-kemungkinan, baik yang telah terjadi maupun kemungkinan-kemungkinan yang akan terjadi dan berpikir jauh ke depan, membuat rencana ke depan dan merencanakan suatu strategi yang tepat (Keating dalam Kimmel dalam Soetjiningsih, 2004). Kemudian pada tabel 3 dapat dilihat bahwa sebagian besar responden menggunakan indikator menentang masalah (confrontative), yaitu 48 orang $(53,93 \%)$ pada strategi koping yang berpusat pada masalah. Banyaknya penggunaan indikator konfrontasi menunjukkan bahwa remaja di rumah tahanan cenderung asertif dalam mengubah keadaan atau masalah yang dirasakan akibat penahanan. Selain itu, hal tersebut juga menggambarkan tingkat kemarahan dan pengambilan risiko oleh remaja dalam penyelesaian masalah. Menurut Hurlock (1980), pengungkapan marah pada periode remaja tidak lagi dengan cara yang meledak-ledak melainkan dengan menggerutu, tidak mau berbicara atau dengan suara keras 
mengritik orang yang menyebabkan marah. Remaja tidak meledakkan emosinya di hadapan orang lain melainkan menunggu waktu dan tempat yang lebih tepat untuk mengungkapkan emosinya. Banyaknya indikator konfrontasi ini digunakan oleh remaja di rumah tahanan menjelaskan bahwa mereka telah belajar menggunakan berbagai kegiatan di rumah tahanan untuk menyalurkan emosinya, seperti pesantren, olah raga, acara ketrampilan atau hanya menonton televisi di ruangan. Walaupun demikian, penggunaan strategi koping yang berpusat pada masalah ini lebih sedikit bila dibandingkan dengan strategi koping yang berpusat pada emosi. Hal ini disebabkan karena remaja tersebut tidak mempunyai sumber koping yang memadai dalam menyelesaikan masalah akibat penahanan ini. Hal ini sesuai dengan pendapat Lazarus dan Folkman (1984) bahwa strategi koping yang berpusat pada masalah adalah upaya yang digunakan untuk pemecahan masalah yang efektif ketika seseorang mempunyai kesempatan yang realistis dalam mengubah situasi mereka dan mengurangi stres. Tabel 2 menunjukkan bahwa penggunaan strategi koping yang berpusat pada masalah dan emosi digunakan secara bersamaan oleh remaja laki-laki di rumah tahanan, yaitu oleh 35 orang $(39,33 \%)$ atau hampir setengah responden. Hal ini sesuai dengan teori dari Lazarus dan Folkman (1984) yang menyebutkan bahwa strategi koping yang berpusat pada masalah dan emosi dapat digunakan secara bersamaan dalam mengatasi masalah yang dialami oleh seseorang. Individu cenderung menggunakan strategi koping yang berpusat pada masalah dalam menghadapi masalah-masalah yang menurutnya bisa dikendalikan. Kemudian jika individu dihadapkan pada masalah yang menurutnya sulit dikendalikan maka individu cenderung menggunakan strategi koping yang berpusat pada emosi (Lazarus dan Folkman, 1984). Dalam mengembangkan strategi koping tersebut, hal ini sangat berhubungan dengan sumber koping. Menurut Lazarus dan Folkman (1984), sumber-sumber koping tersebut terdiri dari kekuatan energi, keyakinan yang positif, kemampuan menyelesaikan masalah, kemampuan sosial, dukungan sosial dan sumber materi. Meskipun sudah menggunakan kedua jenis strategi koping tersebut, masih terdapat sebagian kecil remaja di rumah tahanan yang tidak menggunakan keduanya secara bersamaan, yaitu oleh 29 orang $(32,58 \%)$. Artinya, remaja di rumah tahanan memiliki kecenderungan menggunakan salah satu strategi koping saja atau cenderung tidak menggunakan keduanya. Hal ini bisa disebabkan karena kurangnya sumber koping dan ketidakmampuan remaja tersebut untuk menggunakan upaya-upaya penguasaan terhadap situasi yang dihadapinya (Smet, 1994). Di rumah tahanan, seseorang tidak 
memiliki banyak pilihan untuk mengatasi tekanan yang dialami. Remaja laki-laki di rumah tahanan harus mengikuti dan mematuhi berbagai peraturan yang sangat berbeda ketika mereka berbeda di luar rumah tahanan. Mereka juga mengalami isolasi sosial yang mengakibatkan mereka tidak mempunyai partisipasi sosial di masyarakat akibat pemenjaraan. Sumber koping yang ada hanya terbatas di dalam rumah tahanan itu sendiri, yang jumlahnya juga terbatas, seperti dukungan pihak rumah tahanan yang jumlahnya hanya sedikit, kegiatan-kegiatan yang diadakan dengan waktu yang terbatas. Selain itu, remaja-remaja tersebut tidak memiliki kemampuan untuk menyelesaikan masalah yang dihadapinya. Hal ini bisa disebabkan hampir setengah responden, yaitu 37 responden $(41,57 \%)$ hanya menempuh pendidikan hingga bangku SMP. Pendidikan yang ditempuh seseorang mempengaruhi strategi koping yang digunakan oleh seseorang (Isaacs, 2005).

\section{DAFTAR PUSTAKA}

Agustiani, Hendrianti. 2006. Psikologi Perkembangan Pendekatan Ekologi Kaitannya dengan Konsep Diri dan Penyesuaian Diri pada Remaja. Bandung: Refika.

Arikunto, Suharsimi. 2002. Prosedur Penelitian: Suatu Pendekatan Praktik Edisi Revisi V. Jakarta: PT. Rineka Cipta.

\section{KESIMPULAN}

Hasil penelitian strategi koping pada remaja laki-laki di Rumah Tahanan Kelas I Bandung menunjukkan bahwa remaja laki-laki di Rumah Tahanan Kelas I Bandung menggunakan strategi yang berpusat pada masalah dan emosi atau menggunakannya secara bersamaan, menggunakan strategi koping yang berpusat pada masalah, dan menggunakan strategi koping yang berpusat pada emosi. Berdasarkan hasil penelitian diharapkan pemberi layanan kesehatan meningkatkan perhatian mengenai kondisi internal dan eksternal pada remaja lakilaki di Rumah Tahanan Kelas 1 Bandung. Perawat juga diharapkan dapat melaksanakan asuhan keperawatan yang optimal, sehingga remaja laki-laki di Rumah Tahanan Kelas I Bandung dapat memberikan respon yang adaptif dalam menjalani masa penahanan. Pengkajian lebih lanjut mengenai faktor-faktor yang mempengaruhi penggunaan strategi koping perlu dilaksanakan untuk membuat strategi koping yang efektif untuk remaja lakilaki.

Atmasasmita, R. 1995. Kapita Selekta Hukum dan Kriminologi. Bandung: Mandar Maju.Azwar, Saifudin. 2004. Reliabilitas dan Validitas. Yogyakarta: Pustaka Pelajar.

Badan Pusat Statistik. 2009. Population of Indonesia. Tersedia di:http://www.bps.go.id/sector/populat ion/ (diakses 30 Maret 2009) 
Danim, S. 2000. Metodologi Penelitian untuk Ilmu-IImu Perilaku. Jakarta: Bumi Aksara.

Direktorat Jendral Pemasyarakatan. 2009. Grafik Rata-Rata Jumlah Narapidana Anak Indonesia. Tersedia di: www.direktoratjendralpemasyarakatan. htm (diakses 15 Juni 2009).

Hasriyati, Lina; Agus Sutarna; Suharyati Samba. 2004. Pengalaman narapidana dalam menyesuaikan diri terhadap dampak psikososial di lembaga pemasyarakatan. Majalah Keperawatan. 5:52-64.

Hurlock, Elizabeth. 1998. Psikologi Perkembangan: Suatu Proses Pendekatan Sepanjang Rentang Kehidupan Edisi 5. Jakarta: Erlangga.

Isaacs, Ann. 2005. Panduan Belajar Keperawatan Kesehatan Jiwa dan Psikiatrik Edisi 3. Jakarta: EGC

Kaplan, H.I; B.J. Saddock. 1997. Synopsis of Psychiatry Behavioral Sciences Clinical Psychiatry 7th Edition. Baltimore: Williams \& Wilkins.

Kartono, Kartini. 1999. Patologi Sosial I. Jakarta: PT. Raja Grafindo Persada.

Kartono, Kartini. 2003. Patologi Sosial II: Kenakalan Remaja. Jakarta: PT. Raja Grafindo Persada.

Lazarus, Richard S.; Susan Folkman. 1984. Stress, Coping and Appraisal. New York: Springer Publishing Company, Inc

Nies, M.A. 2001. Community Mental Health Nursing. Lipincolt: Saunders Company.

Norwood. 2000. Research Strategies for Advanced Nurses. New Jersey: Prentice Hall.
Notoatmodjo, S. 2002. Metodologi Penelitian Kesehatan. Jakarta: Rineka Cipta.

Potter, Patricia A.; Anne Griffin Perry. 2005. Buku Ajar Fundamental Keperawatan: Konsep, Proses dan Praktik. Jakarta: EGC.

Pramadi, Andrian dan Hari K. Lasmono. 2000. Koping Stress pada Etnis Bali, Jawa, dan SundaAnima Indonesian Psychological Journal. 2:326-340.

Rasmun. 2004. Stres, Koping dan Adaptasi: Teori dan Pohon Masalah Keperawatan. Jakarta: EGC

Ratri, Palupi Kartikaning. 2008. Hubungan Harga Diri dengan Kecemasan pada Narapidana Anak dalam Menghadapi Kecemasan di Rumah Tahanan Kelas I Bandung. Bandung: Fakultas IImu Keperawatan Universitas Padjadjaran.

Rinita, Nita. 2004. Kehidupan Penjara Anak. Tersedia di www.kompas.com (diakses tanggal 30 April 2009)

Simatupang, Hamaria Mendrofa; Irmawati. 2006. Dinamika Faktor-Faktor Psikososial pada Residivis Remaja Pria (Studi Kasus Remaja Pria di Lembaga Pemasyarakatan Anak Tanjung Gusta Medan). Tersedia di: www.usu.ac.id/id/files/artikel/dinamika faktor irma.pdf (diakses tanggal 30 April 2009)

Smet, B. 1994. Psikologi Kesehatan. Jakarta: PT. Gramedia Widia Sarana Indonesia

Soetjiningsih, dkk. 2004. Tumbuh Kembang Remaja dan Permasalahannya. Jakarta: Sagung Seto. 
Stuart, Gail W.; S.J. Sundeen. 1995. Principles and Practice of Psychiatric Nursing 5th Edition. St. Louis: Mosby.

Stuart, Gail W.; S.J. Sundeen. 1998. Buku Saku Keperawatan Jiwa. Jakarta: EGC.

Stuart, Gail W. 2006. Buku Saku Keperawatan Jiwa. Jakarta: EGC

Sugiyono. 2006. Metode Penelitian Administrasi. Bandung: CV. Alfabeta.

Sugiyono. 2009. Statistika untuk Penelitian. Bandung: CV. Alfabeta.
Tanti, Rias. 2007. Stress dan Kehidupan Penghuni Lembaga Pemasyarakatan. Jurnal Ilmiah Kebijakan Hukum. 1:73-85.

Widyastuti, Palupi. 2003. Manajemen Stres. Jakarta: EGC

World Health Organization. 2000. What about Boy?. Tersedia di: http://whqlibdoc.who.int/hq/2000/WH O FCH CAH 00.7.pdf (Diakses 20 April 2009) 